Crespo-Martin, C., Martin-Gonzalez, F., Yazdi, P., Hainzl, S., Rincon Ramos, M. (2021): Time-

dependent and spatiotemporal statistical analysis of intraplate anomalous seismicity: SarriaTriacastela-Becerrea (NW Iberian Peninsula, Spain). - Geophysical Journal International, 225, 1, 477-493.

https://doi.org/10.1093/gji/ggaa595 


\title{
Time-dependent and spatiotemporal statistical analysis of intraplate anomalous seismicity: Sarria-Triacastela-Becerreá (NW Iberian Peninsula, Spain)
}

\author{
Cristina Crespo-Martín ${ }^{\oplus},{ }_{1}$ Fidel Martín-González ${ }^{\oplus},{ }_{1}$ Pouye Yazdi, ${ }^{2}$ Sebastian Hainzl ${ }^{3}$ \\ and Marta Rincón ${ }^{1}$ \\ ${ }^{1}$ ESCET Área de Geología, Universidad Rey Juan Carlos (URJC), C/Tulipán s/n, Móstoles, 28933 Madrid, Spain. E-mail: cristina.crespo@urjc.es \\ ${ }^{2}$ ETSI Topografia, Geodesia y Cartografia, Universidad Politécnica de Madrid (UPM), C/Mercator 2, Campus Sur, 28031 Madrid, Spain \\ ${ }^{3}$ GFZ German Research Center for Geosciences, Telegrafenberg, 14473 Potsdam, Germany
}

Accepted 2020 December 10. Received 2020 November 13; in original form 2020 September 1

\begin{abstract}
SUMMAR Y
The Sarria-Triacastela-Becerreá seismicity is located in an intraplate region considered seismically stable, but in 1995 started an unprecedented earthquake activity in the area. Since then an anomalous long-term continuous seismicity remains until now in the same location. Despite the long-term seismicity and the large magnitudes for the region standards $\left(5.1 M_{\mathrm{w}}\right)$, the origin and mechanisms of this seismicity remains unclear. The isolation of background from the main shock-aftershock contribution by means of the application of the Epidemic Type Aftershock Sequences (ETAS) model, the spatial depiction and the resemblance to near seismic regions allow us to identify several seismicity behaviours. From 1995 to 1998/99, the seismicity in this location mainly consists of intensive and deeper earthquake sequences linked to the 1995 and 1997 main shocks. Our results suggest that the main shocks triggered aftershocks and additionally initiated or facilitated aseismic processes. A likely scenario is that the main shocks broke a sealed source at depth allowing a subsequent intrusion of high-pressurized fluids from depth. The resemblance of this period with Zamora seismic characteristics proposes that Triacastela seismicity was also initiated by tectonic activity. From 1998/99 to 2018, a change in seismicity is observed, the background contribution took control and swarm-type activity is predominant. While the earthquake rate decreases, the relative background contribution goes up. Actually, after 2013 the clusters almost disappear and background contribution achieves 55 per cent of the total activity. The spatial migration to the southeast and the upward trend to shallower depth support fluid migration as possible driving mechanism responsible for the transient seismicity in this period. The swarm-type activity in Triacastela in later periods and the resemblance of $b$-values with Ponte Caldelas and Ventaniella seismicity suggest that the seismicity in Triacastela is related to fluid migration and the reactivation of fractured areas. We propose that the mechanism of this anomalous and long-term seismicity in Triacastela is the mix of different mechanisms, starting with the tectonic seismicity, generated during the 1995 and 1997 seismic sequences, which initiated a fluid upward migration through fractured crustal fault patches, observed after 1998-1999, and responsible for the seismicity during the following $20 \mathrm{yr}$.
\end{abstract}

Key words: Spatial analysis; Statistical seismology; Intra-plate processes; NW Iberian Peninsula; Ventaniella - Zamora; Lugo.

\section{INTRODUCTION}

Sarria-Triacastela-Becerreá location (henceforth Triacastela) registers one of the most significant seismic instrumental activity in the Iberian Peninsula (the Sarria-Triacastela-Becerreá seismicity or Lugo seismic sequences) (Martín-González 2005;
Martínez-Díaz et al. 2006; López-Fernández et al. 2012; MartínGonzález et al. 2012). Considered as a seismically stable region, belonging to an intraplate area, in 1995 November started a clustered seismicity never registered before in the area. This long-lasting clustered seismic activity continues until the present time (over $25 \mathrm{yr}$ ) and comprises 48 per cent of the total seismic moment release 
in the NW Iberian Peninsula $\left(4.2 \times 10^{24} \mathrm{~N} \cdot \mathrm{m}\right.$, e.g. Martínez-Diaz et al. 2006; Martín-González et al. 2012; Crespo-Martín \& MartínGonzález 2019). This unusual long-term seismicity together with the earthquakes of 5.1 and 4.6 $M_{\mathrm{w}}$ in 1997 May awake the interest of the research community, and even yield updating the Spanish Building Codes, rising the seismic potential of the region (NCSE 2002). So far, researchers mainly studied the geological and tectonic setting, while a statistical analysis of the seismicity is missed which might help to explain the long-term activity and the underlying mechanism (e.g. Martínez-Diaz et al. 2006; López-Fernández et al. 2012; Martin-González et al. 2012).

Statistical methods are broadly used to analyse seismicity and to identify the earthquake generation mechanism (van Stiphout et al. 2012). Interactions between earthquakes allow distinguishing two contributions to the seismicity: aftershocks triggered by main shocks (dependent events) and background earthquakes (independent events) (Ogata 1988). Dependent events are related to stress changes induced by main shocks, while the background seismicity can be attributed to tectonic stress build-up and to transient aseismic forcing related, for example, to fluid migration or slow-slip events (Hainzl et al. 2013; Passarelli et al. 2016). The Epidemic Type Aftershock Sequence (ETAS) proposed by Ogata (1988) is a statistical model that accounts for these background and earthquake triggered contribution separately (Ogata 1988). The declustering of the catalogue, based on the ETAS model, is a tool to separate the two groups (Zhuang et al. 2002; van Stiphout et al. 2012). While the standard ETAS assumes a constant background rate, Hainzl \& Ogata (2005) and later Marsan et al. (2013) modified the ETAS model to invert for a time-dependent background rate. The latter approach can help to identify the underlying mechanisms and significant phase changes. Furthermore, spatial depiction can help to identify migration patterns that are related to the underlying mechanism (e.g. Hainzl \& Fischer 2002; Mesimeri et al. 2018).

Thanks to the setting up and updating of the permanent IGN seismic network, mostly in 1988 and 2002, as well as the installation of temporal seismic network (e.g. GASPI, MISTERIOS and GEOCANTABRICA), the database is improved in the region (e.g. López-Fernández et al. 2012; González 2016). The resulting earthquake catalogue allows to apply statistical techniques to explore the reason of the anomalous seismicity. Therefore, the present study considers the application of the statistical methods for characterizing the source of Triacastela seismicity, for the first time.

The purpose of this research is to achieve a better comprehension of the intraplate seismicity in Triacastela and the factors that can be responsible for this unusual and unprecedented seismicity. The originality of this study is the ETAS application in Triacastela to characterize the time-dependent background rate and also the analysis of spatial migration patterns in order to identify the evolution and the underlying mechanism of the seismicity. To understand its seismic peculiarities, we also compare the outcomes of Triacastela statistical analysis with other intraplate locations in the NW Iberian Peninsula (Ventaniella, Zamora and Ponte Caldelas).

\section{GEOLOGICAL AND SEISMOLOGICAL SET TIN GS}

The Triacastela location belongs to an intraplate region, far away from the active seismic plate boundaries of Eurasian Plate and Nubian African Plate, located in the South of Spain (Fig. 1). It is located in a Variscan basement (Palaeozoic and pre-Cambrian in age) deformed by the Variscan Orogeny, and subsequently during Cenozoic times this region suffered the Alpine Orogeny. The Alpine structures are reactivated under the present stress field (NW-SE oriented) and they are the seismogenic faults responsible for the recent seismicity (e.g. Martín-Serrano et al. 1996; Martínez-Díaz et al. 2006; De Vicente et al. 2008; Martín-González \& Heredia 2011; Martín-González et al. 2012). The NW Iberian Peninsula is the western termination of the Alpine Pyrenean-Cantabrian Orogen whose activity migrated westward starting during the middle Eocene in Asturias to the Early Oligocene in Galicia (Martín-González \& Heredia 2011; Martín-González et al. 2014). After the middle-Miocene, the deformation migrated to the southern plate boundary and the region suffered the far-field effects of the southern border (Betics chains, Galindo-Zaldivar et al. 1993; Martín-González et al. 2012). The spatial distribution of seismicity and focal mechanisms show that faults trending NE-SW to N-S and NW-SE seem to be responsible for most of the present seismicity (e.g. López-Fernández et al. 2004; Martínez-Diaz et al. 2006; Martín-González et al. 2012). In the NW Iberia (e.g. Zamora, Ventaniella), the reactivation of alpine structures are also responsible for the main seismicity (Martín-González et al. 2012; López-Fernández et al. 2018).

The NW Iberian Peninsula is a region with recent moderate intraplate seismicity $\left(5.1,4.9\right.$ and $\left.4.6 M_{\mathrm{W}}\right)$. The Triacastela location alone released 48 per cent of the total seismic moment in the whole region and it registers the highest magnitudes (5.1 and $4.9 M_{\mathrm{w}}$ in 1997 May and 2 events of 4.6 $M_{\mathrm{w}}$ in 1995 November and December). Seismicity in the NW Iberia is scattered and clustered. 62 per cent of the seismic moment released in those clusters. The clustered seismicity, in turn, is classified by swarms and main shockaftershock sequences (Fig. 1). Swarms contribute 69 per cent of the clustered seismicity (Crespo-Martín \& Martín-González 2019). The high proportion of energy releases in Triacastela compared to the surrounding and the long-term unprecedented seismicity, gave us the clue to analyse the activity in Triacastela more specifically by means of an ETAS model accounting for time-dependent forcing (Crespo-Martín \& Martín-González 2019).

\section{DATA}

The current study includes data from the most actives seismic regions in NW Iberian Peninsula: Triacastela in Lugo [Latitude $42^{\circ} 36^{\prime} 0^{\prime \prime}, 43^{\circ} 17^{\prime} 60^{\prime \prime}$ and Longitude $\left.7^{\circ} 27^{\prime} 36^{\prime \prime} \mathrm{W}, 7^{\circ} 0^{\prime} 0^{\prime \prime} \mathrm{W}\right]$, Zamora [Latitude $41^{\circ} 42^{\prime} 48^{\prime \prime}, 41^{\circ} 23^{\prime} 60^{\prime \prime}$ and Longitude $6^{\circ} 12^{\prime} 28^{\prime \prime} \mathrm{W}$, $5^{\circ} 47^{\prime} 59^{\prime \prime} \mathrm{W}$ ], Ponte Caldelas in Pontevedra [Latitude $42^{\circ} 27^{\prime} 00^{\prime \prime}$, $42^{\circ} 17^{\prime} 30^{\prime \prime}$ and Longitude $\left.8^{\circ} 41^{\prime} 16^{\prime \prime} \mathrm{W}, 8^{\circ} 25^{\prime} 56^{\prime \prime} \mathrm{W}\right]$ and southern inland trace of the Ventaniella fault in León [Latitude $43^{\circ} 0^{\prime} 0^{\prime \prime}$, $42^{\circ} 53^{\prime} 60^{\prime \prime}$ and Longitude $\left.5^{\circ} 30^{\prime} 0^{\prime \prime} \mathrm{W}, 4^{\circ} 54^{\prime} 00^{\prime \prime} \mathrm{W}\right]$ (Fig. 1). The period used for our analysis starts in 1988 and finishes in 2018, with special focus on activity after 1995 when significant activity occurred (see Section 5).

The data source for Triacastela, Zamora and Ponte Caldelas is provided by the Spanish National Earthquake Catalogue that is compiled by Instituto Geográfico Nacional (IGN), agency responsible for the Seismic Network and earthquake catalogue (IGN 2020http://www.ign.es/web/ign/portal/sis-catalogo-terremotos). For the southern of Ventaniella fault region, we used the earthquake catalogue of López-Fernández et al. (2018) which is based on temporary stations of the projects MISTERIOS (Integrated monitoring of the earth system in Spain: seismic research and observation network) and GEOCANTABRICA (Modelling geological processes of the relief of the Cantabrian Mountains). 


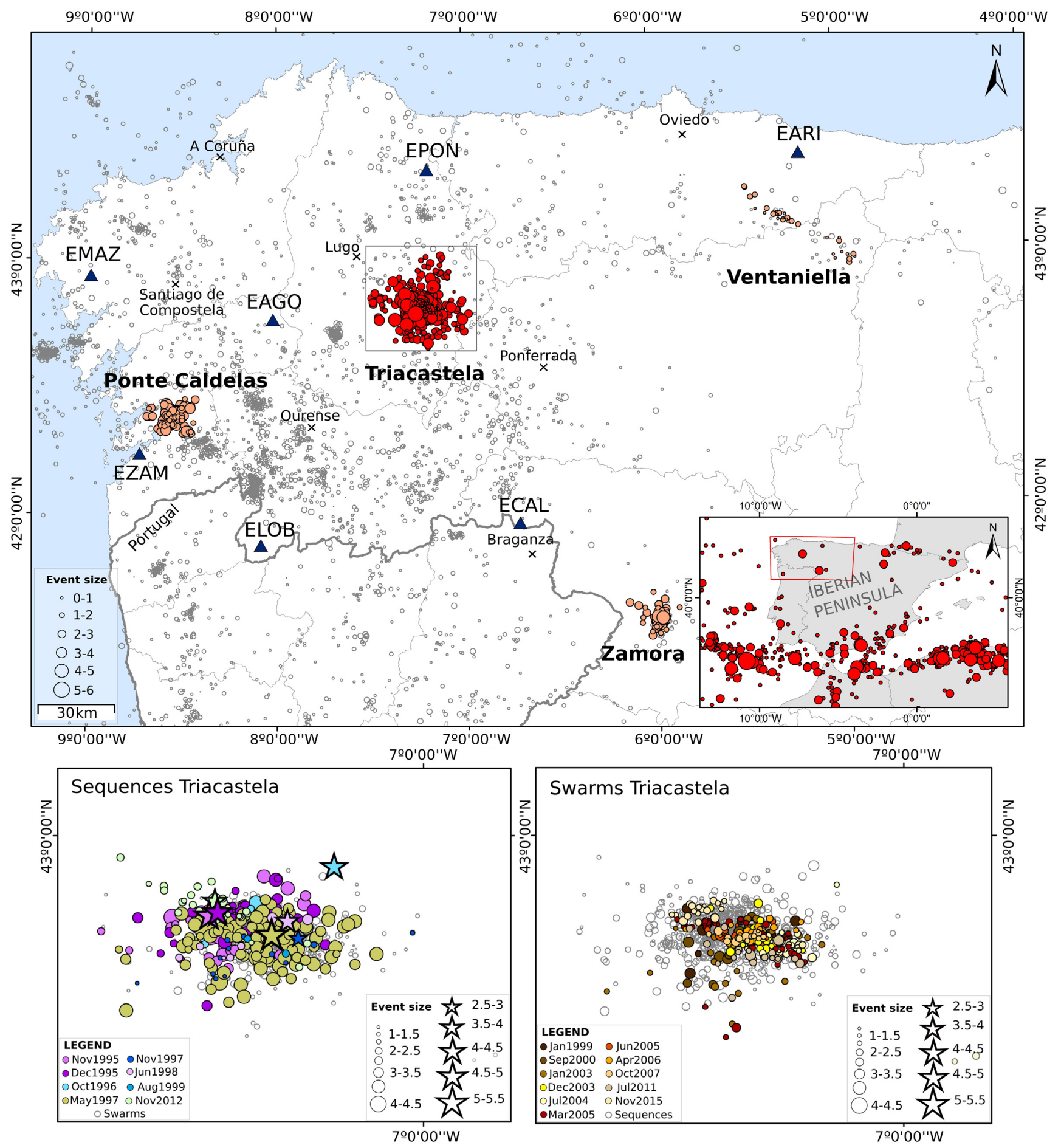

Figure 1. (a) Location of Triacastela, Ventaniella, Ponte Caldelas and Zamora in the NW Iberian Peninsula (Spain). Red points depict the studied seismicity of Triacastela and in pink the other locations studied. Triangles are the actives IGN stations on 2018 September 30. Inset the location of NW in the Iberian Peninsula. On the bottom is shown the clustered seismicity of Triacastela, (b) the sequences in cold colours and (c) the swarms in warm colours. The remainder seismicity, IGN data set, is drawn scaled in grey tones.

\section{EVOLUTION OF IGN SEISMIC NET WOR K}

The IGN has developed the seismic alert network stations over the years, including in the NW Iberian Peninsula. The first seismic station in the studied region opened in 1972 in Santiago de Compostela and the first event registered by this station was in 1979. To complete the coverage, from 1985 to 1988, three short-period stations were set up close to Triacastela location: EMAZ (Zamans -Pontevedra), ERUA (A Rua-Ourense) and EMON (Mondoñedo-Lugo) (Fig. 2). Continuous recording and quality are ensured since 1988. Another remarkable shift of the seismic network took place in 2002, with the installation of six new broad-band stations: ELOB (Lobios-Ourense), EARI (ArriondaAsturias), EPON (Pontenova-Lugo), ECAL (Calabor-Zamora), 


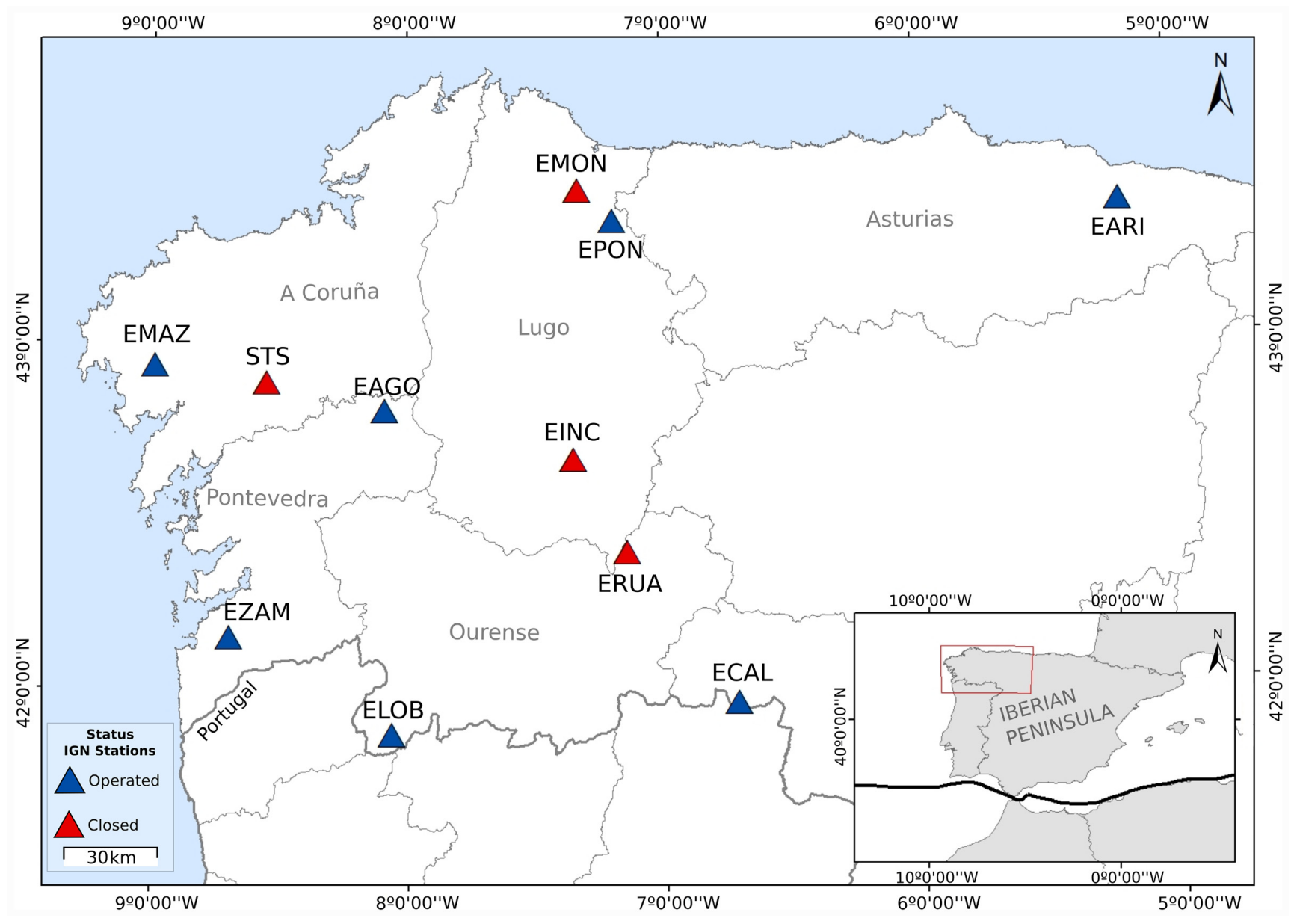

Figure 2. Map with the location of IGN Seismic Network of NW Iberian Peninsula. Blue triangles IGN stations working and red triangles IGN stations closed on the studied period. Inset location of NW Iberian Peninsula. Black line depicts the boundary of Eurasian Plate (north) and Nubian African Plate (south) (by USGS).

EMAZ (Mazaricos-A Coruña) and EINC (O Incio-Lugo) (Fig. 2, González 2016; IGN 2020). These new installations led to a significantly densified recording which we take into consideration in our analysis of the seismic catalogue.

\section{BUILDING THE CATALOGUE}

\subsection{Homogenized and completed catalogue}

Due to the instrumentation improvements, the events have been registered in different magnitude scales (MbLg (M-MS), mb (V-C), $\mathrm{mbLg}$ (L) and $M_{\mathrm{w}}$ (González 2016). For the comparison of the data, a homogenization of the earthquake size parameter into Moment Magnitude $\left(M_{\mathrm{w}}\right)$ is required. We have homogenized the catalogue using the updated equations of the Spanish Seismic Hazard Map (IGN-UPM 2013; Cabañas et al. 2015).

Our study includes a long time period of seismicity, from 1995 to 2018 , so the evolution of the network is crucial because of the completeness of the catalogue is directly related to it. The Magnitude of Completeness $\left(M_{\mathrm{c}}\right)$ represents the magnitude threshold above which all earthquakes are likely recorded in the catalogue. Drastic fluctuations on $M_{\mathrm{c}}$ throughout the time indicate changes of the seismic network and thus in the recorded seismicity (Gulia et al. 2012). To detect the relevant changes in Triacastela, we plot the evolution of estimated $M_{\mathrm{c}}$ together with the registered seismicity
(Fig. 3). The estimation of $M_{\mathrm{c}}(\mathrm{t})$ is made with ZMAP tool in MATLAB, developed by Wiemer (2001), where we use the Maximum Curvature (MAXC) technique (Mignan \& Woessner 2012).

A substantial change of $M_{\mathrm{c}}(t)$ and seismicity takes place in 2002 caused by the upgrade of the seismic network (Figs 2 and 3). For this reason, we have split the seismic catalogue analysis of Triacastela in two phases. The Phase 1 (before 2002) covers from 1995 November when the first clustered seismicity started (no significant seismicity is recorded before) to the late 2001 (2001 December) when the seismic network was upgraded. The Phase 2 (after 2002) begins with the developments in the seismic network and ends in late 2018 September (Fig. 3).

Before 2002 the estimated $M_{\mathrm{c}}$ is 3.2 and after 2002, the $M_{\mathrm{c}}$ drops to 1.8 when smaller earthquakes started to be registered (Fig. 3). Disregarding the atypical seismicity from 1995 to 1997, around 29 events were registered each year before 2002, which greatly increase to 94 events $\mathrm{yr}^{-1}$ after 2002 . The significant difference of $M_{\mathrm{c}}$ before and after 2002 together with the raise of registered events, suggests to carry out an independent statistical analysis (Figs 3 and 4). The $b$ values before and after 2002 are higher than the unit ( $1.40 \pm 0.01$ and $1.15 \pm 0.04$, respectively) that reflect a fractured crust region that could be associated with high pore pressure (Fig. 4).

Once the magnitude is homogenized and filtered based on threshold magnitude for the two phases, the catalogue is prepared to use in the temporal analysis. 
Seismic Network change

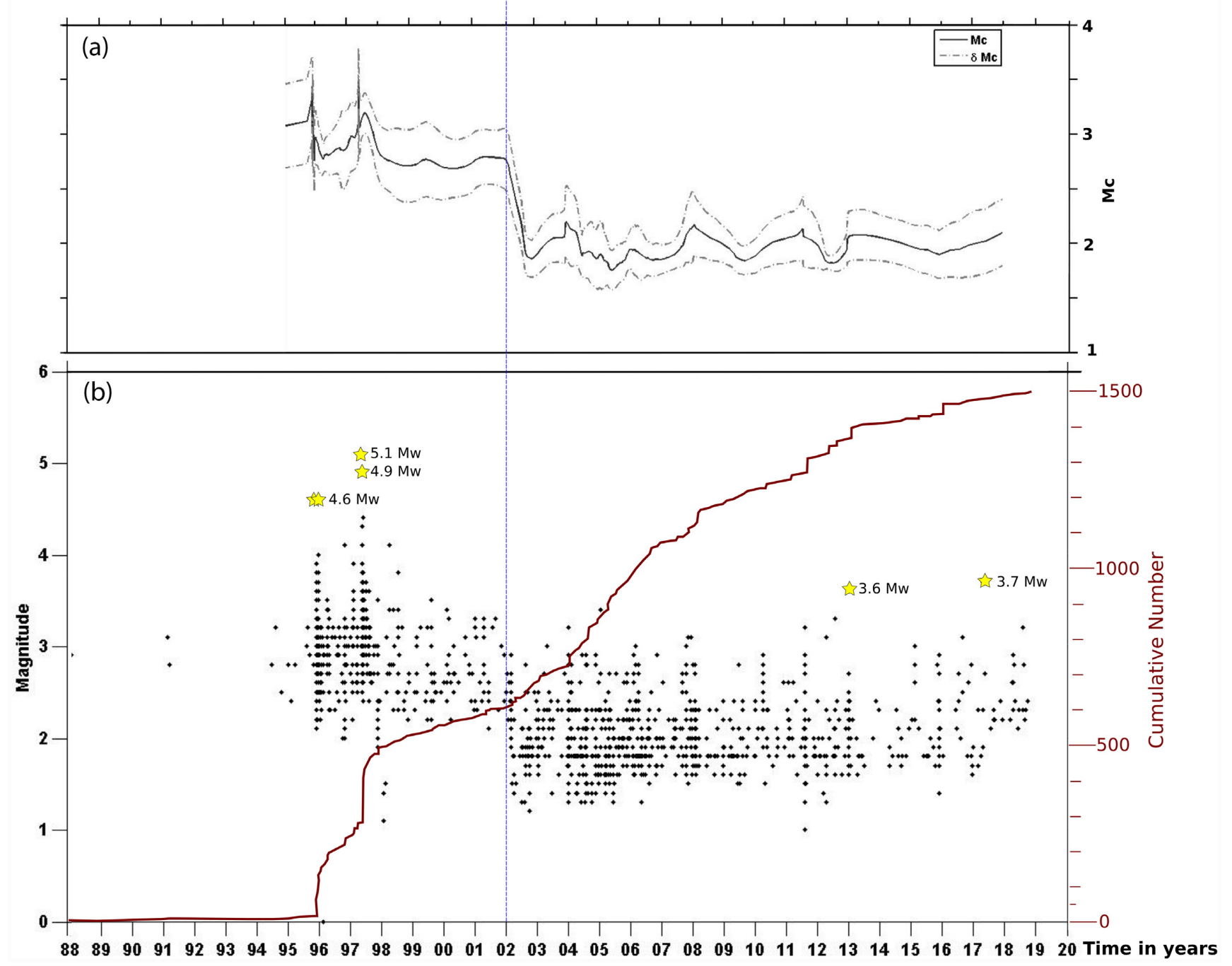

Figure 3. (a) Evolution of $M_{\mathrm{c}}$ and (b) seismicity from 1988 to 2018. (a) Black line is $M_{\mathrm{c}}$ fluctuations and dotted lines are the standard deviations of $M_{\mathrm{c}}$. (b) Magnitude of earthquakes (black points) and the highest ones (stars). Red line is the cumulative number of events.

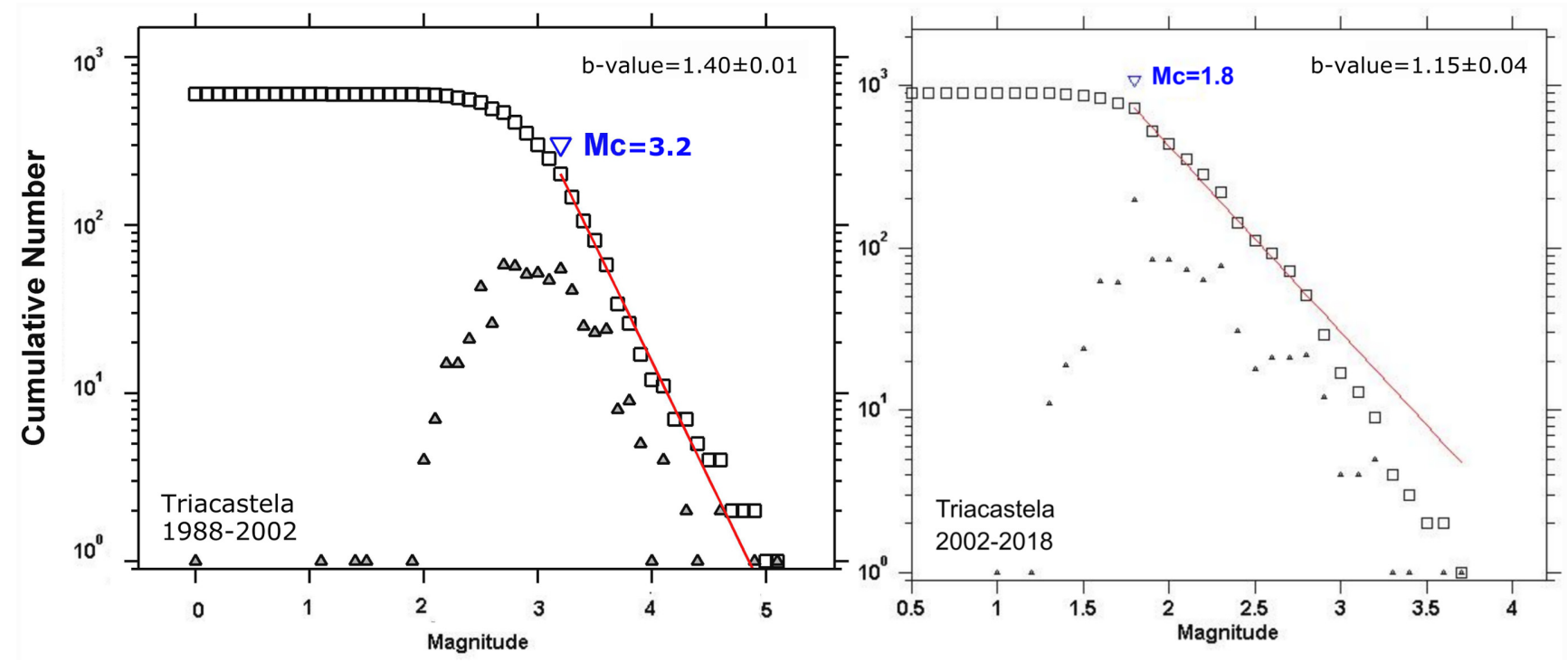

Figure 4. Estimation of Magnitude of Completeness (MAXC method) to Tricastela before 2002 (left) and after 2002 (right). 


\subsection{Relocated catalogue}

Analysing the spatial migration is also an important tool to define the generation process of the seismicity, for instance the tectonic influence, diffusion of fluids or slow slip events (Hainzl \& Fischer 2002). Such space-time analysis of clusters in Triacastela requires very accurate hypocentral coordinates. For these reasons, we relocated the clusters in Triacastela, and the resulting catalogue is used for the spatial analysis (see Section 6.3).

\section{METHODOLOGY}

\subsection{Time dependent background ETAS model}

The ETAS proposed by Ogata (1988) is a point-process model widely used for the analysis and modelling of short-term earthquake clustering (e.g. Ogata 1988; Zhuang et al. 2012; Marsan et al. 2013) (eq. 1). It is considered that the rate of earthquakes is provoked by two contributions: (i) the aseismic forcing $(\mu)$ or also called rate of background earthquakes and (ii) the earthquake-earthquake interaction term (v) assuming that each earthquake can trigger its own offsprings (e.g. Ogata 1988, 1998; Zhuang et al. 2012),

$\lambda(t)=\mu+v=\mu+K \sum_{t_{i}<t} \frac{e^{\alpha\left(m_{i}-M_{c}\right)}}{\left(t-t_{i}+c\right)^{p}}$

where the second term sums over all earthquakes $i$ (with occurrence time $t_{i}$ and magnitude $m_{i}$ ) occurred before time $t$. The parameters $\mu, \alpha, K, c$ and $p$ explain several characteristics of seismic activity (Ogata 1998). The $\alpha$-value (magnitude ${ }^{-1}$ ) denotes the efficiency in generating aftershock by an event of specific magnitude. $K$ is related to the productivity of an event with threshold magnitude $M_{\mathrm{c}}$, while c (unit of time) and $p$-value determine the decay rate. All of them are based on the Omori--Utsu aftershock decay law (Ogata 1988, 1998; Zhuang et al. 2011, 2012; Marsan et al. 2013).

The method of Marsan et al. (2013) establishes an optimization approach to determinate the time-varying forcing rate, $\mu(t)$. Based on the ETAS model (eq. 1), they used an iterative algorithm able to determinate both ETAS parameters and time-dependent background by using the maximum-likelihood estimate (MLE) with an $n$-nearest-neighbour smoothing of the background rates.

To balance the increasing degree of freedom for decreasing $n$ values and the increasing fit quality, the Akaike Information Criterion (AIC) is used (Helmstetter \& Sornette 2003; Marsan et al. 2013; Yazdi et al. 2017).

$\mathrm{AIC}=2 k-2 \ln (L)$

where $L$ is the maximum-likelihood value of the model fit and $k$ is the number of free model parameters.

The application of this method in Triacastela sheds light on the characteristics of seismicity and generation mechanisms. Particularly in small areas of clustered activity, this method can unveil background rate oscillations over the time (Marsan et al. 2013). Large magnitude events lead to aftershocks and can also initiate aseismic processes which are reflected in an increase of the background rate. Without a main shock, a constant, sudden or gradual onset defines the generation process of the seismicity. A constant $\mu(t)$ unravels a continuous tectonic loading rate as typically occurring in active fault systems. A sudden onset is blame for aseismic process like rapid fluid intrusion or slow slip events. A more gradual trend in the background rate is attributed to slow transient deformation (Marsan et al. 2013).

\subsection{Declustering}

This process allows to isolate dependent seismicity (aftershockmain shock) and independent events (background). The separating is based on spatiotemporal proximity between earthquakes, prior shocks and/or the highest seismicity rate compared to the long-term average rate (van Stiphout et al. 2012). The methods are based either on deterministic or on stochastic criterion. In the first case, the earthquakes are defined either as main shock or aftershock according their space-time distance, while stochastic algorithms use the ETAS model to calculate probabilities (Zhuang et al. 2002; van Stiphout et al. 2012).

In this paper, we use the probabilistic ETAS-approach (eq. 1) based on the method proposed by Marsan et al. (2013). The application of this algorithm which accounts for time-dependent background, is the most appropriate method for our study area where the seismicity patterns vary with time (Hainzl \& Ogata 2005; Hainzl et al. 2013). The result provides a probability per event of being a background or aftershock, $p_{i}=\mu\left(t_{i}\right) / \lambda\left(t_{i}\right)$, varying between 0 (no background) and 1 (background). The estimated cumulative number of background events is the sum of these probabilities.

\subsection{Relocation of events}

A double-difference relocation method is applied in this study, particularly we used the HypoDD algorithm defined by Waldhauser \& Ellsworth (2000). It is a package in Fortran language to relocate pair of events based on $P$ - and $S$-waves traveltimes differences at several stations as well as the initial locations $(x, y, z)$ and origin times $(\tau)$.

The initial data for the relocations is taken from the catalogue data provided by the IGN. As input data for HypoDD, we provide the $P$ - and $S$-wave time arrivals and the stations coordinates. Due to the large number of events (more than 100 events), we solve the DD equations with the conjugate gradient method (LSQR, Paige \& Saunders 1982; Waldhauser 2001). We are aware of the underestimation of the errors with this method. To assess the accuracy of the results, we split up the seismicity of Triacastela into clusters (Fig. 1) and recalculated the hypocentre relocation in these small systems with the singular value decomposition technique, as suggested by Waldhauser (2001). The outcomes revealed quite similar distribution of events between both methods. The HypoDD is designed to relocate the internal structure of the seismicity (relative relocation), while the absolute location is not perfectly defined. We consider that the relocations for the split data set well estimate the location inside the cluster but not the relative locations between different clusters. However, for the migration analysis we need to compare the location between clusters, so we used the relocation data of the whole seismicity.

For our statistical space-time analysis, we used our relocations for Triacastela, while we used for Ventaniella the relocated events of López-Fernández et al. (2018). For both cases, the relocations were obtained by HypoDD. In Triacastela 1475 earthquakes were registered from 1988 January to 2018 September from which 975 earthquakes could be relocated (Figs 8 and 9). The standard deviation achieves a maximum of $\pm 0.46 \mathrm{~km}(E x), \pm 0.66 \mathrm{~km}(E y)$ and $\pm 0.70 \mathrm{~km}(E z)$. In Ventaniella 45 events were registered from 2015 October to 2017 March with 37 relocations by HypoDD (López-Fernández et al. 2018).

\subsection{Spatial depiction}

In this paper, the clusters definition of swarm or main shockaftershock (also called sequence) is founded on the classification 
defined by Mogi (1963). Based on the shape of the frequencymagnitude distribution along with the presence of a prominent main shock or the lack of it, Mogi defines clusters as swarm or sequences (Mogi 1963; Utsu 1971).

Large fluctuations in time can appear in the background rate which is typical for earthquake swarms generated by fluid migration (Hainzl \& Ogata 2005). Even though theses swarms have no clear main shock, a hypocentral migration is occasionally noted in them as a trademark of fluid migration movement or slow-slip events (Marsan et al. 2013). Looking for migration of the seismicity which is explained by fluid migration, we analyse the space-time clusters previously defined. We use the GIS ArcGis10.4 to plot the spatial seismicity of Triacastela and the regions of Ventaniella, Zamora and Ponte Caldelas. Considering a possible migration of the background and aftershock seismicity, we use the ETAS-based probabilities for classification and a Python 3 code for plotting them as well as depth histograms.

\section{ANALYSIS OF TEMPORAL SE IS M I C I T Y}

\subsection{Triacastela seismicity: before 2002}

The declustering tool allows us to separate the background and aftershock contribution using probabilistic estimations. Before 2002, the completeness magnitude is estimated as $M_{\mathrm{c}}=3.2$, leading to a set of 206 earthquakes with $m \geq 3.2$ (Fig. 4). While we fit the ETAS model only to events after 1995, we consider that aftershocks in the fitting period were potentially triggered by earthquakes prior to 1995 . For these events, we use $m \geq 3.2$ events from the homogenized catalogue occurred since 1979 when the first event was registered. The ETAS modelling of this data set leads to a minimum AIC-value for a smoothing window of $n=6$. This small optimal smoothing length indicates that the background rate varied sharply over time in this period, revealing two different trends (Fig. 5).

Prior to 1998, the background rate is clearly non-stationary. The sudden fluctuations of background rate is similar to the variations in the cumulative number of all events, which correlates with the largest earthquakes of 1995 November and 1997 May. The large clusters seem to be not alone explained by aftershock sequences but also an additional aseismic forcing (such as migration of fluids) which drives the seismicity (Figs 5 and 6).

After 1998, the trend changes and linear regression totally fits to the cumulative background seismicity, indicating a constant background stressing rate which seems to be independent of the aftershock activity produced by the highest events (Fig. 5).

The related ETAS parameters are provided in Fig. 5 and Table 1. While $K, c$ and $p$ are in the range of ETAS parameters typically observed at plate boundaries, the $\alpha$-value of 1.15 is significantly lower than the values around 2 which are related to pure main shock-aftershock sequences (Hainzl \& Marsan 2008).

Considering the evolution of background rate as function of time and the occurrence of the main shocks in 1995 November and 1997 May, we distinguish two subperiods: subperiod 1 (1995Nov1997Oct) and subperiod 2 (1997Oct-2002Jan) (Figs 5 and 6).

\section{Subperiod 1 (1995Nov-1997Oct):}

In this subperiod, the highest number of events are registered (178 earthquakes with $M_{\mathrm{c}} \geq 3.2$ ). Our analysis shows that the seismicity is non-stationary during the main shocks-aftershocks sequences of 1995 November-December and 1997 May-October, while it followed a stationary trend in the middle from 1996 February to 1997 April (Figs 5 and 6, and Table 2).

The background rate shows abrupt jumps related to the three sequences associated with the largest main shocks occurred in (1) 1995 November 29 (4.6 $\left.M_{\mathrm{w}}\right)$, (2) 1995 December $22\left(4.6 M_{\mathrm{w}}\right)$ and (3) 1997 May 21 (5.1 and 4.9 $M_{\mathrm{w}}$ ). The promotions in the cumulative number of background events reflects a strong increase of the seismicity rate in these dates. Apart from these sudden jumps, the background rate is almost stationary from 1996 February to 1997 April, with an approximatively constant background rate of $\mu(t) \approx$ 10 (1/yr) events with $m \geq 3.2 \mathrm{yr}^{-1}$ (Figs 5 and 6). Two short-term increases of the background rate are linked to the earthquakes of 1996 October $\left(4.1 M_{\mathrm{w}}\right)$ and 1997 February $\left(3.9 M_{\mathrm{w}}\right)$. The almost constant background rate over time points to a continuous, tectonictype loading of the fault system.

\section{Subperiod 2 (1997Oct-2002):}

This subperiod includes 23 earthquakes which appear to follow a stationary process with a linear increase of the cumulative number of background events (Fig. 5), and respectively a stable background rate (Fig. 5, bottom panel and Fig. 6, right-hand panel). Compared to the previous subperiod, both the total and the background rates are drastically decreased. The total rate is reduced by a factor of approximately 18 , whereas the background rate is decreased by a factor of almost 4 (Table 2).

\subsection{Triacastela seismicity: after 2002}

Likewise in the time before 2002, the declustering of the catalogue allows us to separate background or aftershock characteristics of the seismicity in Triacastela. However, the improvement of the seismic network enables us to detect smaller events that yield lower $M_{\mathrm{c}}$ in comparison to time before 2002. Therefore, after 2002, more events are registered (1325 earthquakes) with magnitude higher than the completeness magnitude of 1.8 (Table 1). The ETAS modelling for this phase, using with $M_{\mathrm{c}}=1.8$, reveals a further remarkable change in the seismic properties.

The ETAS fit for this period is optimal for a smoothing window of $n=66$ which minimizes the AIC-value. The significantly larger smoothing window compared to the first period indicates a rather stationary seismicity with a slowly changing background rate in time. Similarly to the first period, approximately 50 per cent of the events are identified as aftershocks and the ETAS parameters $c, p$ and $K$ are in the range of values for tectonic plate boundaries, while the $\alpha$-value is significantly lower (0.94) (Table 1). The stationary seismic activity which started in the beginning of 1998 continues after 2002, but with successively decreasing rates (Fig. 7). The earthquake clustering almost disappears since 2003 and the background contribution takes control of the seismicity (Fig. 7).

Based on the slope changes in the cumulative number of background events over time, the period after 2002 can be divided in three subperiods. Subperiod 3-from 2002 January to 2008 December, subperiod 4-from 2009 January to 2012 December and subperiod 5-from 2013 January to 2018 September (Figs 6 and 7).

\section{Subperiod 3 (2002Jan-2008Dec):}

This subperiod is defined by the highest number of events, 395 earthquakes, and also covers the longest time period. Besides, it registers the highest frequency of event with an average slope of 65.7 earthquakes of $m \geq 1.8 \mathrm{yr}^{-1}$. In this period, the ETAS modelling yield the estimation that around 46 per cent of seismicity is related to background activity with an almost constant rate of 33.9 events 

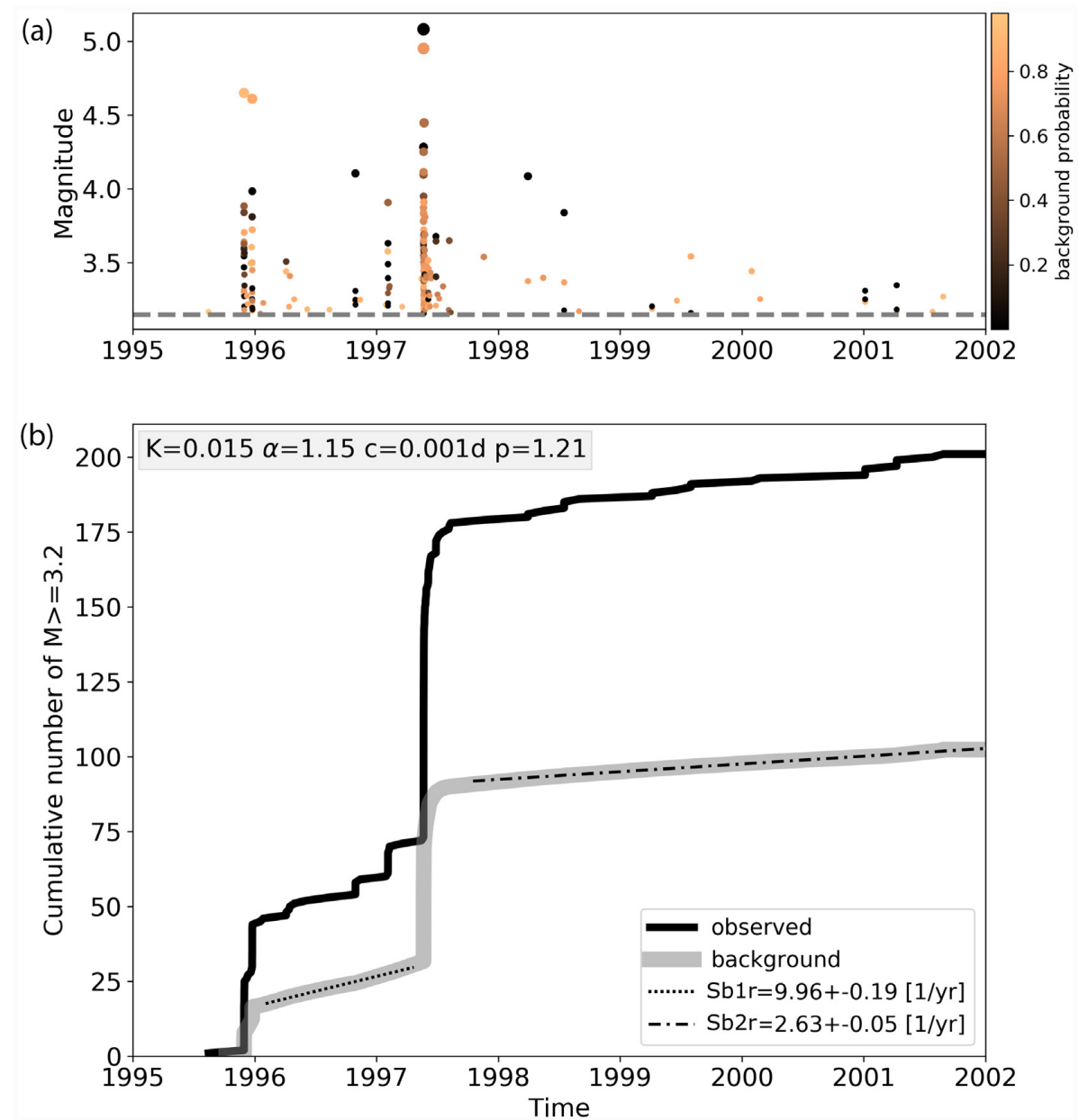

Figure 5. Declustering of the catalogue before 2002. (a) The magnitude against time with scaled colours based on background probability from 1995 to 2002. Orange probability of being background (near 1.0) and black aftershock seismicity (close to 0.0). Dotted line denotes $M_{\mathrm{c}}=3.2$. (b) Cumulative number of observed events with $M_{\mathrm{c}} \geq 3.2$ (black line) and cumulative number of background events (grey line). Background rate of subperiod 1 (Sbr1) and for subperiod 2 (Sbr2) are depicted in dotted and dotted-dashed lines. The ETAS result is shown in the grey box.

$\mathrm{yr}^{-1}$ (Figs 6 and 7, and Table 2). This rate can be compared to the rate before 2002 (with $M_{\mathrm{c}} \geq 3.2$ ) by multiplying the values by the Gutenberg-Richter factor $10^{-b\left(M c_{1}-M c_{2}\right)}=10^{-1.4 b}=0.0246$ using the estimated $b$-value of 1.15 . This leads to a background rate of 0.83 for $M_{\mathrm{c}}=3.2$, which is more than three times smaller than the estimated value in the last period before 2002. Whether this decrease is real or only related to the uncertainties in the extrapolation is not fully clear.

\section{Subperiod 4 (2009Jan-2012Dec):}

This subperiod includes 202 earthquakes with $m \geq 1.8$. The total earthquake rate is also reduced to 40 events $\mathrm{yr}^{-1}$, while the background contribution continues to be 46 per cent with a rate of 185 events with $m \geq 1.8 \mathrm{yr}^{-1}$. Regardless of the fluctuations in the background rate and assuming the same $b$-value of $1.15, \mu(t)$ is equivalent to 0.46 events $\mathrm{yr}^{-1}$ with $m \geq 3.2$, which is less than in the third subperiod $\left(0.83\right.$ events $\left.\mathrm{yr}^{-1}\right)$, see Table 2 .

\section{Subperiod 5 (2013Jan-2018):}

This subperiod includes even less earthquakes (125) for $m \geq 1.8$. The total earthquake rate indicates an approximate rate of 22 events $\mathrm{yr}^{-1}$, which marks a further reduction with respect to the precursory period (Table 2). A slightly larger fraction (55 per cent) of those events are related to an almost constant background activity with a rate of 11.5 events $\mathrm{yr}^{-1}$. Compared to subperiod 4, with a rate of 18.5 events $\mathrm{yr}^{-1}$, this is a reduction by a factor of 1.6.

Regardless of the fluctuations and assuming the same $b$-value of 1.15 , in the subperiod 5, the background rate is around 0.3 events with $m \geq 3.2$. While the rate is decreased relative to the prior subperiods, the relative contribution of the background seismicity to the total activity contribution increased and became 55 per cent of the seismicity (Fig. 6 and Table 2).

Comparing the whole time period from 1995 to 2018, the ETAS analysis shows that the activity started with some rapid periods of transient aseismic forcing which simultaneously occurred with the largest observed earthquakes. After those periods, the seismicity became stationary, but with successively decreasing background rates in the four subsequent time periods.

\section{ANALYSIS OF SPATIAL SEISMICITY AND BACKGROUND}

The transient fluctuations of the background rate, especially in swarm activity, are sometimes connected to hypocentre migration. Several researchers asserted that this spatial migration is related to fluid movement or slow earthquakes (Hainzl 2004; Vidale \& Shearer 2006; Lohman \& McGuire 2007; Wolfe et al. 2007; 

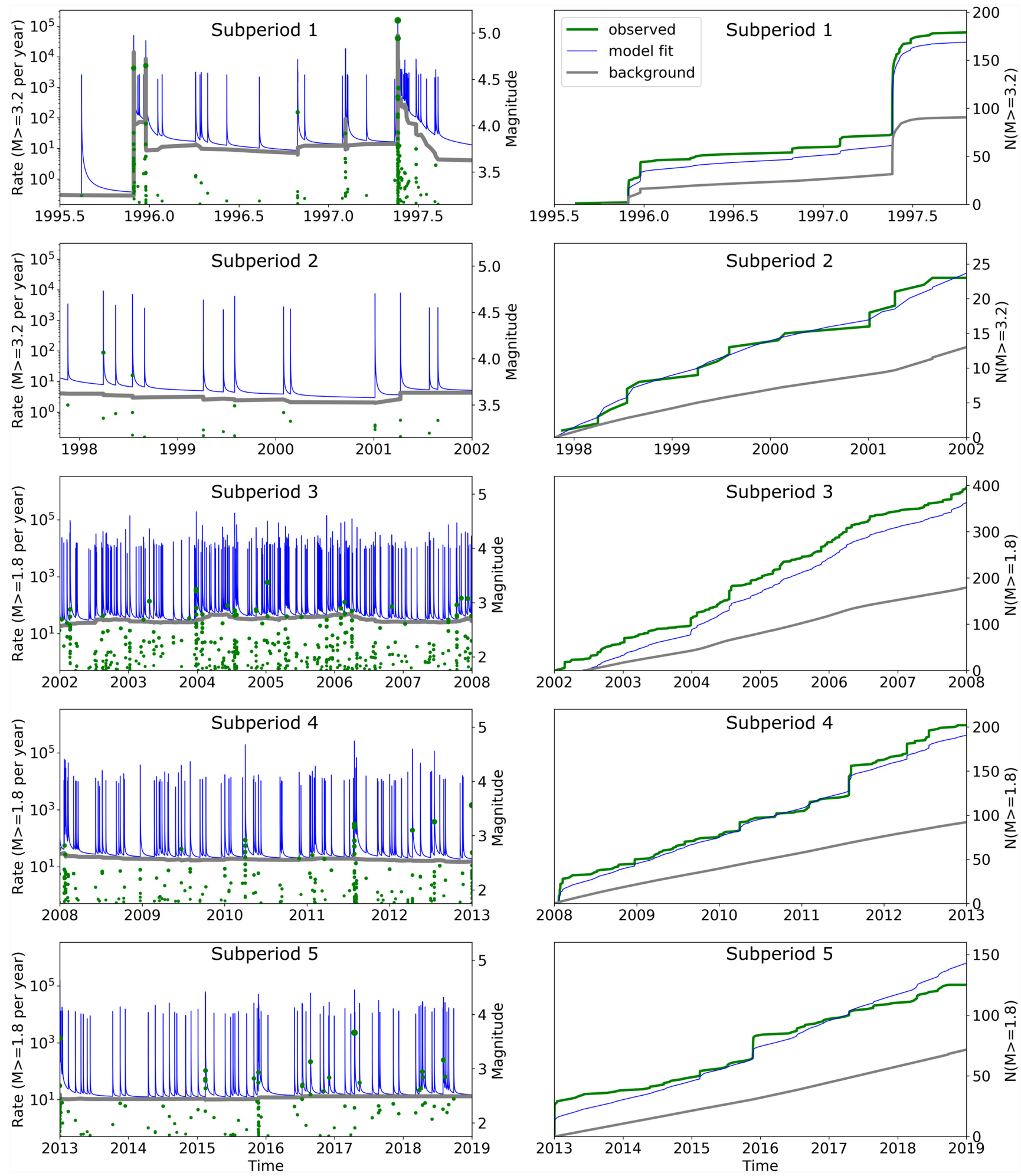

Figure 6. Background seismicity over time for subperiods before 2002 (subperiods 1 and 2) and after 2002 (subperiods 3, 4 and 5). At left-hand column, background rate (grey line) on log scale over the temporal seismicity (green points). The total ETAS rates at the given times, $R(t)=\mu(t)+v(t)$, are shown with the blue line. At right column, temporal cumulative number of events for observed (green), fitted (blue) and background (grey) trends. Note that all time units refer, as in the other figures, to fractions of a year, for example, 1996 refers to 1996 January 01 and 1996.5 to the beginning of 1996 July.

Marsan et al. 2013; Kumazawa et al. 2016). The spatiotemporal pattern of the seismicity complements the temporal activation pattern and may give a further clue of the triggering mechanism (Hainzl \& Fischer 2002; Mesimeri et al. 2018). For such a spatial depiction, a high precision of the hypocentres is required which is fulfilled by our relocated earthquake data set.

Based on the estimated ETAS parameter, we first calculated for all relocated earthquakes the probability for being a background 
Table 1. Temporal ETAS results before $2002\left(M_{\mathrm{c}}=3.2\right)$ and after $2002\left(M_{\mathrm{c}}=1.8\right)$ using the Marsan et al. (2013) algorithm. Earthquakes in the learning period are considered to potentially trigger aftershocks in the optimizing, in which the ETAS model is fitted to the data. ETAS parameters $K, c, \alpha$ and $p$ are also shown in Figs 5 and 7. $n$ refers to the smoothing window that minimize the AIC-value. $N_{\text {obs }}$ and $N_{\text {bg }}$ refer to number of observed earthquakes and estimated background events, respectively.

\begin{tabular}{|c|c|c|c|c|c|c|c|c|c|c|c|}
\hline & Learning period & Optimizing period & $M_{\mathrm{c}}$ & K & $c$ & $\alpha$ & $p$ & $n$ & $N_{\text {obs }}$ & $N_{\mathrm{bg}}$ & $N_{\mathrm{bg}} / N_{\text {obs }}$ \\
\hline 1995-2002 & 19790101-19941231 & $19950101-20011231$ & 3.2 & 0.015 & 0.0009 & 1.15 & 1.2 & 6 & 206 & 102 & 0.50 \\
\hline 2002-2018 & $19790101-20011231$ & $20020101-20180930$ & 1.8 & 0.011 & 0.002 & 0.94 & 1.4 & 66 & 1325 & 342 & 0.26 \\
\hline
\end{tabular}

Table 2. Background rates in subperiods before 2002 (subperiods 1 and 2) and after 2002 (subperiods 3-5). These outcomes are related to the fitted lines in Figs 5 and 7. $\mu(t)$ is the yearly background rate for events with magnitudes above the completeness magnitude $M_{\mathrm{c}}$. The symbol $*$ in the background rate indicates that the estimation is done for the stationary period from 1996 February to 1997 April. To compare the background rates of both time periods, we multiple the $\mu(t)$ after 2002 by the factor $(f)$ of $10^{-\mathrm{b} *(\text { Mcut1-Mcut } 2)}=10^{-\mathrm{b} * 1.4}$, which for $b=1.15$ gives $f=0.0246$. Eq rate (earthquake rate) $=N_{\text {obs }} /$ days. $N_{\text {obs }}$ and $N_{\text {bg }}$ refer to number of observed earthquakes and estimated background events, respectively.

\begin{tabular}{lccccccc}
\hline Before 2002 & Optimizing period & $M_{\mathrm{c}}$ & $\mu(t)$ & $N_{\text {obs }}$ & $N_{\text {bg }}$ & $N_{\text {bg }} / N_{\text {obs }}$ & \\
\hline Subperiod 1 & $19950101-19970930$ & 3.2 & $9.96 *$ & 178 & 91 & 0.51 & \\
Subperiod 2 & $19971001-20011231$ & 3.2 & 2.63 & 23 & 12 & 0.52 & \\
After 2002 & Optimizing period & $M_{\mathrm{c}}$ & $\mu(t)$ & $f * \mu(t)$ & $N_{\text {obs }}$ & $N_{\text {bg }}$ & $N_{\text {bg }} / N_{\text {obs }}$ \\
Subperiod 3 & 20020101-20071231 & 1.8 & 33.92 & 0.83 & 395 & 182 & 0.46 \\
Subperiod 4 & $20080101-20121231$ & 1.8 & 18.5 & 0.46 & 202 & 92 & 0.46 \\
Subperiod 5 & 20130101-20180930 & 1.8 & 11.51 & 0.28 & 125 & 69 & 0.55 \\
\hline
\end{tabular}
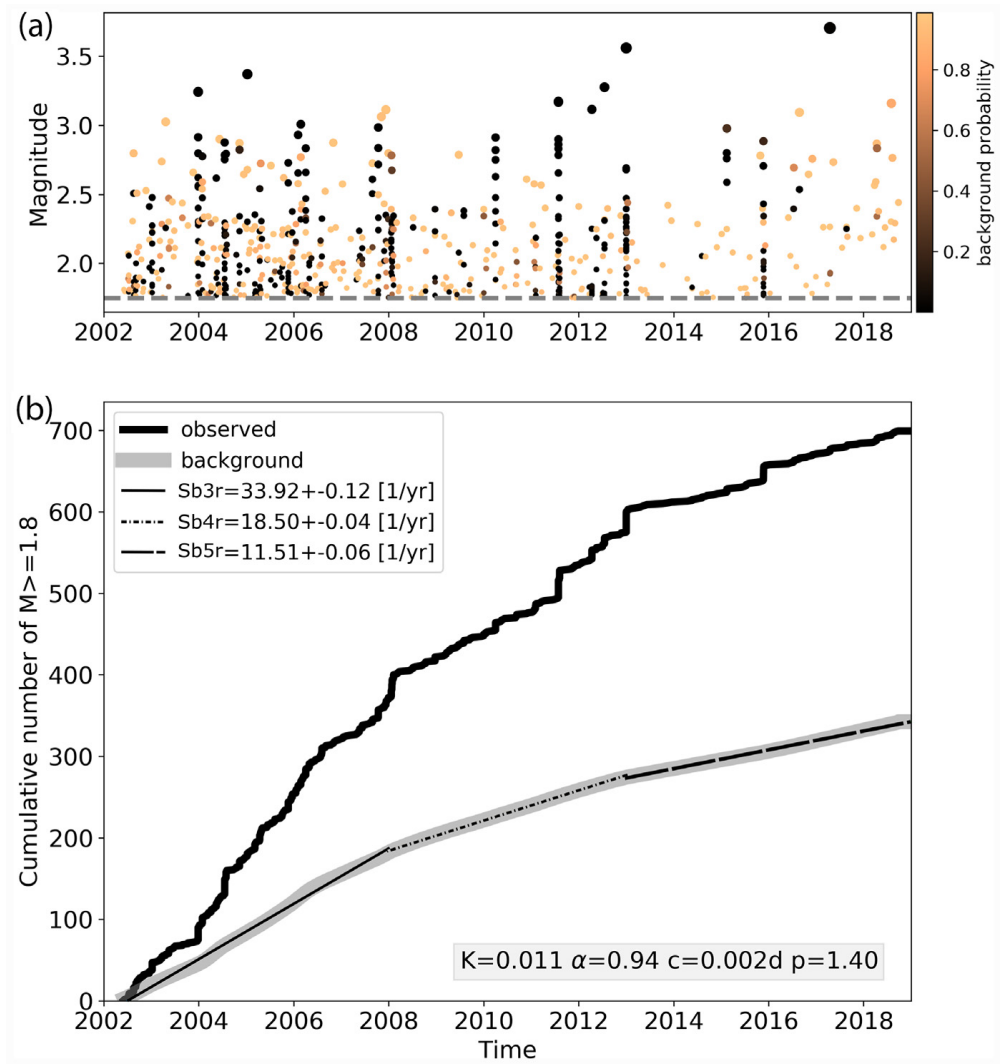

Figure 7. Declustering of the catalogue after 2002. (a) The magnitude against time with scaled colours based on background probability from 2002 to 2018 September. Orange probability of being background (near 1.0) and black aftershock seismicity (close to 0.0). Dotted line denotes $M_{\mathrm{c}}=1.8$. (b) Cumulative number of observed events with $M_{\mathrm{c}} \geq 1.8$ (black line) and cumulative number of background events (grey line). Background rate of subperiod 3 (Sbr3), subperiod 4 (Sbr4) and subperiod 5 (Sbr5) are depicted in solid, dotted-dashed and dashed lines. The ETAS result is shown in the grey box.

event. According to Zhuang et al. (2002), this probability is given by the ratio between background rate and total ETAS rate at the occurrence time (Zhuang et al. 2002). Fig. 8 shows a spatial plot of the relocated seismicity of Triacastela colour-coded by this probability. The plot reflects a general NW-SE orientation of the whole seismicity (Fig. 8). Although the patterns are not very clear, the seismicity pattern indicates a southeastern horizontal migration and a general tendency to become shallower with time. This 
behaviour is indicated by the variation of the spatial distribution in the different time periods and the temporal decrease of the mean depth value as shown in Figs 8 and 9. The upward trend of the events could be the result of fluid flow (Hainzl 2004).

For a more detailed analysis, we separately plot the spatial distribution of the clusters presented in Fig. 1 (Figs 8 and 9). The characteristics change in 1999 and the seismicity turns to a swarm activity, whereas before this date, the aftershock-type sequence activities dominate. Besides, the mean of depth histograms reveal that sequences occurred at depth of about $9 \mathrm{~km}$ and swarms at around $7 \mathrm{~km}$, therefore seismicity is displacing to the shallower crust with time (Figs 8 and 9).

The spatial distribution of swarms and sequences also differs. A general trend of spatial migration along WNW-ESE is recognizable (Fig. 9). The sequences of Tricastela are defined in the northwest and centre, while swarm activity seems to be typically located in the southeast and centre. This migration along with the evolution in the background rate could indicate a transient forcing as for example, fluid migration or slow slip.

\section{OTHER SEISMIC CLUSTERS IN THE NW IBERIAN PENINSULA}

The Triacastella location registers the earthquakes with the largest magnitudes and represents 48 per cent of the total seismic moment released in the region. However, other seismic clusters have been also identified in the region. In this study, a comparison to these further clusters are carried out in order find possible similarities in their source mechanisms proposed in the literature.

Zamora is located $185 \mathrm{~km}$ southeast of Triacastela region (Fig. 1). A remarkable seismicity happened in 1961 with doublet of events with same magnitudes of $5.2 M_{\mathrm{w}}$, and decades later with earthquakes of magnitude 4.2 and $4.4 M_{\mathrm{w}}$ in 2003 January. Since 1998, 123 events have been registered. We focus on the 2003 sequences occurred between January $12-18$ and in July. The seismicity of 2003 January is located in the centre of the region, and it shows a spatial migration to the northeast during the following cluster in July (Fig. 10a). Both Zamora and the first period of Triacastela are defined by aftershock-sequence activity due to the presence of main shocks and it is support by a less than the unity $b$-values in the Zamora clusters (0.72 in 2003 January and 0.88 in 2003 July) (Fig. 10a and Table 3). The sequence-type seismic activity of Zamora is related to the tectonic activity of NNE-SSW strike-slip fault (Martín-González et al. 2012).

Located $113 \mathrm{~km}$ southwest of Triacastela, Ponte Caldelas registers 147 events with two clusters in 2013 October and 2018 May (Figs 1 and 10b). Both clusters are swarm-like, with earthquakes magnitudes between 1.5 and $3.2 M_{\mathrm{w}}$. The spatial distribution of Ponte Caldelas swarms reflects a migration to the north for the seismicity (Fig. 10b). Swarm-type activity is dominant in Ponte Caldelas and can be compared with the second and the third periods of Triacastela (Fig. 10b). The high and close to the unit $b$-values of Ponte Caldelas (1.37 in 2013 October and 0.93 in 2018 May) resemblance to the Triacastela results (Fig. 4 and Table 3). In this region, the existence of thermal springs is well known, and some studies correlate the deep crustal and even mantellic fluids with the seismicity in this area (Pe'rez et al. 1996; Marques et al. 2003; López et al. 2015). These findings could support the result of our statistical analysis and suggest fluid migration as a possible source of seismicity.
Ventaniella seismicity is located $164 \mathrm{~km}$ to the northeast of Triacastela in the same Variscan basement and intraplate context. Based on local seismic network (see Section 3), 37 events were registered from 2015 October to 2017 March (Fig. 1). Following the spatial selection defined by López-Fernández et al. (2018), two clusters Group A with 24 events and Group B with 11 events, are defined and are separately analysed (Fig. 11a). Not only the spatial distances, but also the differences of $M_{\mathrm{c}}$ values in Ventaniella suggest a separated analysis of seismic clusters. In the Group A, the $M_{\mathrm{c}}$ is found to be 1.2, whereas $M_{\mathrm{c}}=0.7$ is found for Group B (Fig. 11b), although there was no change in the seismic network over the whole seismic period, that is, from 2015 October to 2017 March (Fig. 11c). It is not clear whether this difference is related to the different source regions or it is just linked to estimation uncertainties due to the limited event number. The progressive trend of the cumulative number of events in Ventaniella (Fig. 11c) is similar to the Triacastela seismicity after 1998 (Figs 5 and 7). In both cases, the lack of prominent main shock supports a swarm-type activity in Ventaniella (Mogi 1963; Utsu 1971). Similar to Triacastela, the $b$-values are higher than the unit in Ventaniella (1.7 \pm 0.6 and $1.4 \pm 0.3$, Figs 4 and $11 \mathrm{~b})$. The dominant swarm activity and the higher $b$-values of the seismicity in Ventaniella support a resemblance to the Triacastela seismicity after 1998. The seismicity in Ventaniella has been related to fractured areas in the crust and faults intersection (Lopez-Fernandez et al. 2018).

\section{DISCUSSION}

To understand the unusual and unprecedented seismicity in Triacastela, we carried out a detailed ETAS and spatial analysis of the seismicity. Our analysis reveals significant changes in the processes of earthquake generation.

Before 1998/99 (period 1), main shocks occurred in 1995 and 1997 play an important role in triggering significant number of aftershocks, where seismicity parameters are found to be in the range of typical values for tectonic plate boundaries. However, the background rate was highly non-stationary in this period and sudden increases happen during the main shock-aftershock sequences (Figs 5 and 6). The events before 1999 were also deeper than later events and were located north-westward in relation with the complete seismic activity of Triacastela (Figs 8 and 9). These observations suggest that not only the main shock triggered aftershocks by the main shock-induced stress changes, but also additionally induced aseismic transients (e.g. by breaking a sealed source enabling fluid intrusion from depth) which triggered additional earthquakes (background events) in the subsequent phases.

From 1998/99 to 2018 (periods 2 and 3), the background rate became almost stationary (constant forcing) but with a decreasing rate (Figs 6 and 7). The analysis shows that only small clusters with relatively low earthquake magnitudes occurred in this period. The continuous background rate in this period indicates that those clusters, although swarm-like type, can be mainly explained by local aftershock triggering (Fig. 7). Later, between 2002 and 2018, the earthquake rate has decreased over the time by a factor of 3 , whereas the background contribution increased from 46 per cent to 55 per cent (Table 2). Indeed, after 2013 (period 3) the clustered seismicity is almost disappeared and the background contribution remains close to 55 per cent (Fig. 7 and Table 2). The analysis of the spatial distribution shows that after 1999 the seismicity migrated from NW to SE and became shallower (Figs 8 and 9). All these results and 

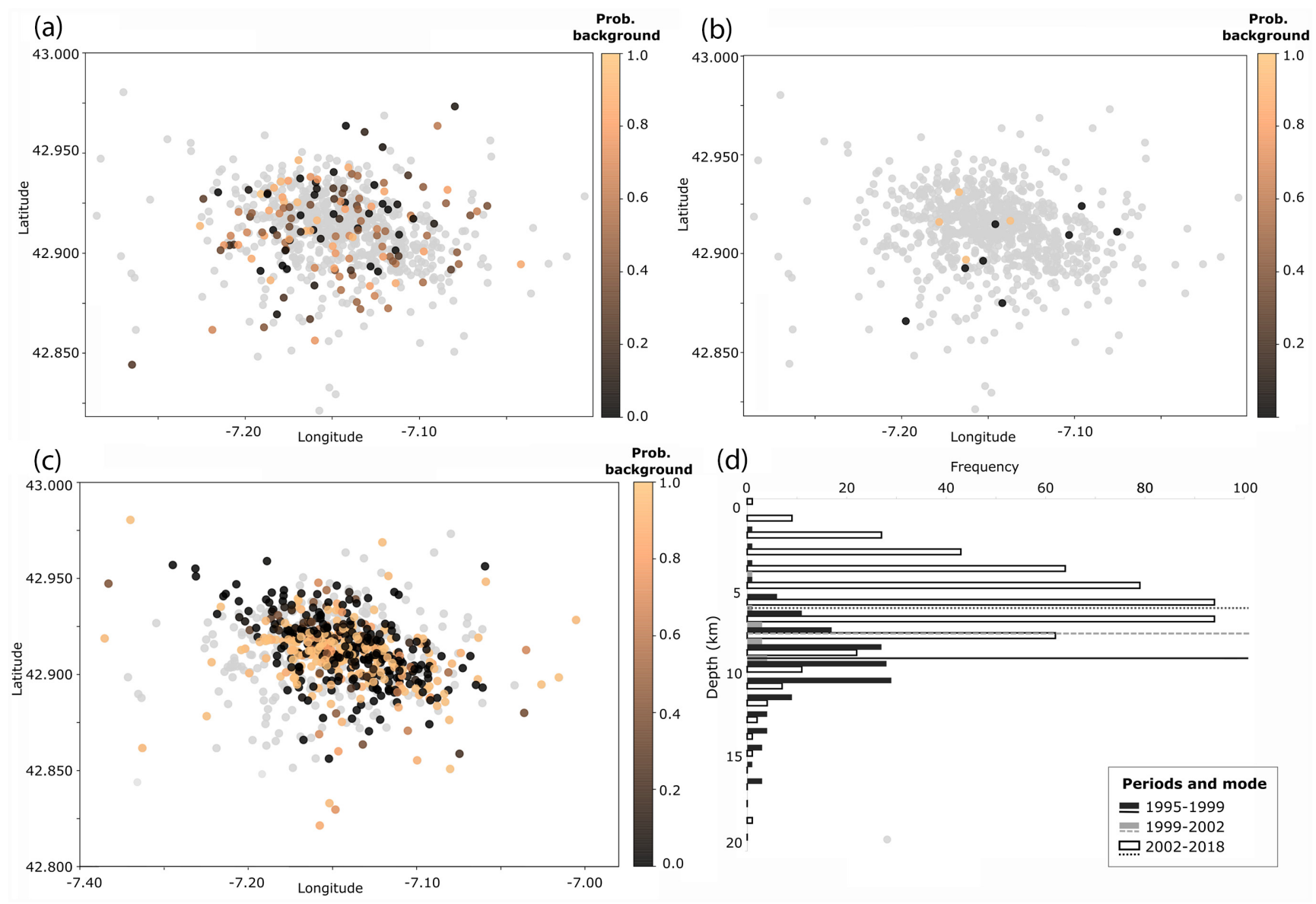

Figure 8. Spatial plot of background and aftershock seismicity (relocated catalogue). Scaled colours are based on background probability (orange) to aftershock (black). Grey points are the whole seismicity. (a) From 1995 to 1999 with $M_{\mathrm{c}} \geq 3.2$. (b) From 1999 to 2002 with $M_{\mathrm{c}} \geq 3.2$. (c) From 2002 to $2018 M_{\mathrm{c}} \geq 1.8$. (d) Histograms of depths $(\mathrm{km})$ per period. The horizontal lines reflect the depth mean [8.8, 7.6 and 5.9 for periods (a), (b) and (c), respectively].

the dominant background seismicity could indicate ongoing, but decreasing aseismic forcing attributed to fluid diffusion or slowslip events initiated in the first phase as it has been also identified in other studies (e.g. Hainzl 2004; Hainzl \& Ogata 2005; Vidale \& Shearer 2006).

Comparing the Triacastela seismicity with other clusters in the same intraplate region of the NW Iberia, it is observed that the first period of seismicity in Triacastela (1995-1998/99) can be compared with the Zamora sequences (Table 3) which have been related to tectonic activity on pre-existing faults (Martín-González et al. 2012). The second and third periods (after 1998/99) are more comparable to the swarm activities of Ponte Caldelas and Ventaniella. They are characterized by swarm-type activity and high $b$-values $(1.2,1.7$ and 1.4, Figs 4 and 11a and b). The events of Ventaniella, which have been related to fractured crustal areas and fault intersections (Lopez-Fernandez et al. 2018), are similar to the second period of seismicity in Triacastela. Ponte Caldelas seismicity is supported by the existence of deep crustal and even mantellic fluids related to the faults (Pe'rez et al. 1996; Marques et al. 2003; López et al. 2015) which due to their length and dip penetrate deep in the crust, allowing the circulation of fluids and increasing fluid pressure. The presence of fluids driving the seismicity in Ponte Caldelas could support the same transient forcing in the near seismic region of Triacastela.
The results of the ETAS and the space-time analyses of the Triacastella seismicity indicate that this activity is related to tectonic processes with an additional aseismic forcing which contributed to the main shock-aftershock sequences until 1998/99. This mix of processes, subsequently triggered the swarm-type activity in later periods, with decreasing rate but with increasing background contribution. These characteristics point to fluid migration that likely started by a fluid intrusion at depth facilitated by the main shock fractures, followed by an upward migration of the fluids. Therefore, the long-term unusual seismicity in this location can be explained with the combination of seismic and aseismic sources. Starting with the tectonic seismicity influence by aseismic force generated during the 1995 and 1997 seismic sequences that were able to trigger the fluids upward migration responsible for the seismicity through a fractured area during 20 more years.

\section{CONCLUDING REMARKS}

For more than $25 \mathrm{yr}$, since 1995, uninterrupted seismicity has been registered in Triacastela, though it has evolved. The segregation of aftershock and background contributions, by means of the timedependent ETAS model and the spatial depiction allow us to identify three periods in the Triacastela seismicity. 


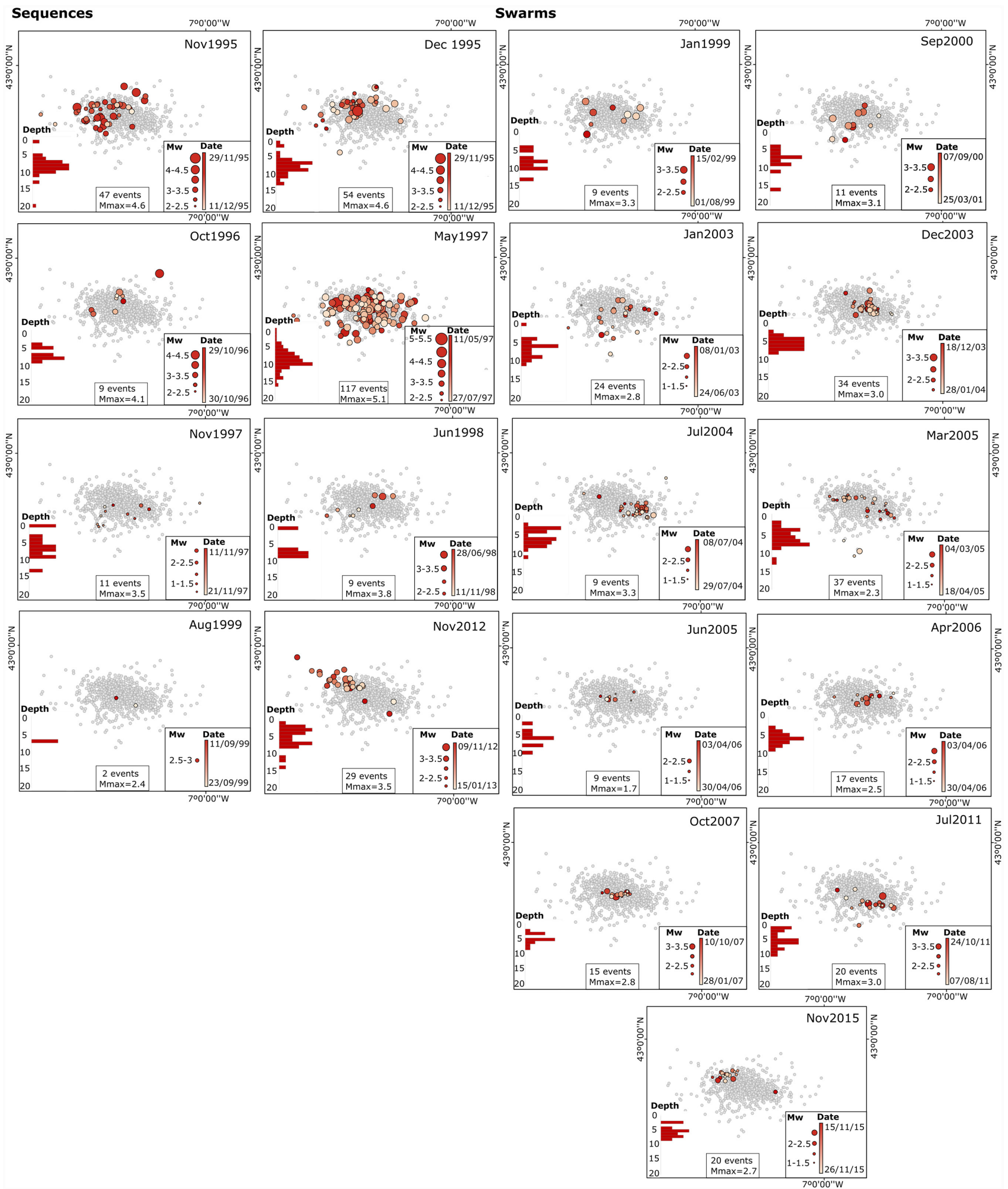

Figure 9. Latitude and longitude portray of clusters in Triacastela based on the relocated catalogue. Sequences (left) and swarms (right). The red points are the events for each cluster and in grey the remainder seismicity. The earthquake size is based on the magnitude. Histograms of depth (km) in red at left.

In the period 1995-1998/99, intensive earthquake sequence dominated the seismicity, particularly related to aftershocks of the main shocks in 1995 and 1997. These main shocks triggered not only aftershocks by their induced stress changes, but also simultaneously initiated or facilitated an aseismic process which strongly contributed to the triggering of the observed activity.

After 1998/99, the aseismic forcing (background contribution) took control of the Triacastela seismicity with a dominance of 
(a)
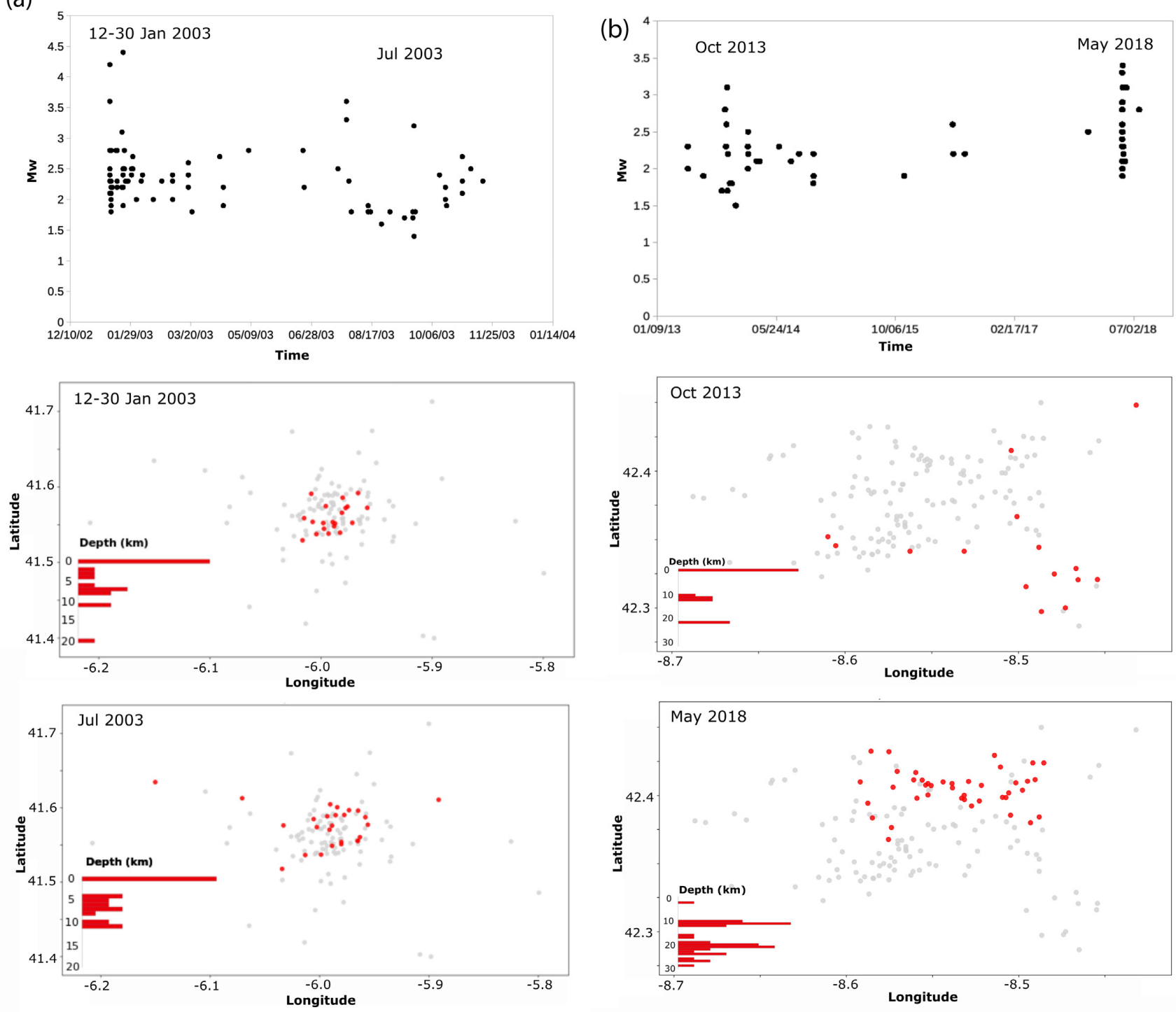

Figure 10. Magnitude-time and latitude-longitude for seismicity in (a) Zamora and (b) Ponte Caldelas. Zamora is split up in the sequences of 2003 January 12-18 and 2003 July. The swarms of Ponte Caldelas of 2013 October and 2018 May are plotted respectively. The red boxes at left are the histograms of depth $(\mathrm{km})$.

Table 3. Mogi classification and Gutenberg-Richter values for clusters of Zamora and Ponte Caldelas.

\begin{tabular}{lcccccc}
\hline \multirow{2}{*}{ Location } & & & Number of & & & \\
Zamora & Name & Data (starting-ending) & events & Mogi name & $M_{\mathrm{c}}$ & $b$-value \\
& Main shock & $20031201-20030119$ & 20 & Sequence & 2.8 & $0.72 \pm 0.4$ \\
Ponte Caldelas & Main shock & $20030720-20031031$ & 26 & Sequence & 1.8 & $0.88 \pm 0.2$ \\
& Swarm & $20131006-20140125$ & 12 & Swarm & 2.2 & $1.37 \pm 0.5$ \\
& Swarm & $20180515-20180602$ & 40 & Swarm & 2.0 & $0.93 \pm 0.1$ \\
\hline
\end{tabular}

swarm-type activity. Even the earthquake rate is decreasing, the background contribution increases more and more, from 46 per cent to 55 per cent. In fact, later 2013 the clusters are almost disappeared and the background contribution achieves the 55 per cent. Therefore, fluid migration is the possible driving mechanism responsible of the seismicity in this period.

Thus, our analysis of the seismicity in Triacastela and the comparison to other seismic activities in NW Iberian Peninsula suggest that the underlying triggering process is a mix of seismic mechanisms, starting with the tectonic seismicity and aseismic forcing, generated during the 1995 and 1997 seismic sequences. A likely scenario is that the main shocks broke a sealed source at depth allowing a subsequent intrusion of high-pressurized fluids from depth. Their clusters were able to trigger fluid upward migration through a fractured crustal area observed after 1999 (deep crustal and even mantellic fluids related to the fault activity and highly fractured 

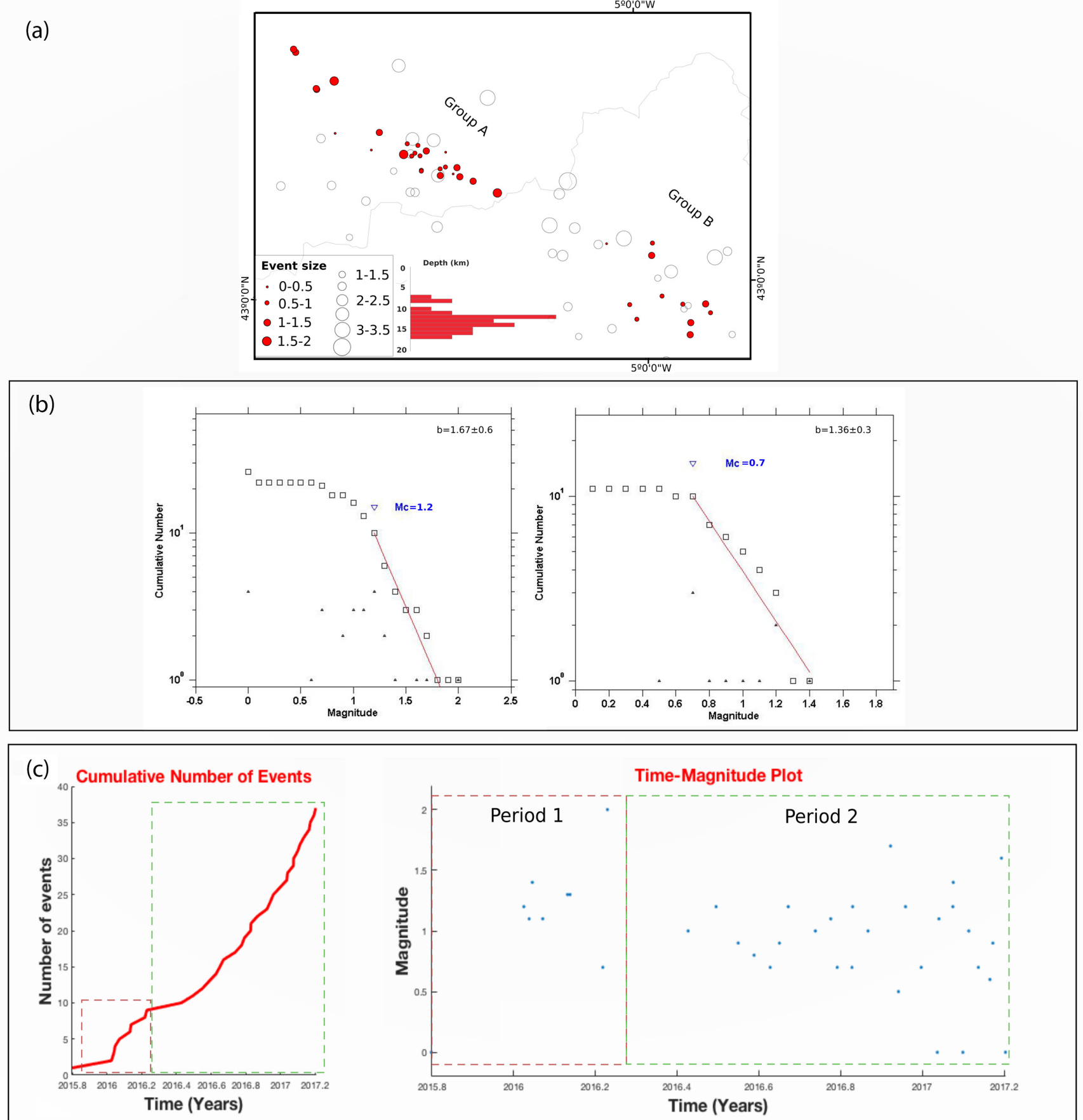

Figure 11. (a) Spatial earthquakes of Ventaniella proportional to magnitude $M_{\mathrm{W}}$ based on database of Lopez-Fernández et al. (2018). The northern cluster is Group A and the southern's the Group B. Histogram of depths $(\mathrm{km})$ at left. (b) Estimation of Magnitude of Completeness (MAXC method) to Ventaniella for Group A (left) and Group B (right). (c) Ventaniella cumulative events and time-magnitude plots for the Period 1 (pink dotted line) and Period 2 (green dotted line).

crust are observed in the region), and responsible for the seismicity during the following $20 \mathrm{yr}$.

\section{ACKNOWLEDGEMENTS}

This work was supported by the Spanish Ministry of Economy and Competitiveness and FEDER Funds of the European Union [project CGL2015-70970-P] and the Community of Madrid and
Funds of European Union [grant award by PEJD-2017-PRE/AMB3472]. The authors are grateful to Juan Vicente Cantavella (Spanish National Geographic Institute) for his technical support in the relocation procedure. The data source for Triacastela, Zamora and Ponte Caldelas is provided by the Instituto Geográfico Nacional (IGN), agency responsible for the Seismic Network and earthquake catalogue, and belonging to the Spanish Ministry of Transport, Mobility and Urban agenda (IGN 2020 - http://www.ign.es/web/ign/portal/ sis-catalogo-terremotos). For Ventaniella, we used the earthquake 
catalogue of López-Fernández et al. (2018) which is based on temporary stations of the projects MISTERIOS (Integrated monitoring of the earth system in Spain: seismic research and observation network) and GEOCANTABRICA (Modelling geological processes of the relief of the Cantabrian Mountains).

\section{REFERENCES}

Cabañas, L., Rivas-Medina, A., Martínez-Solares, J.M., Gaspar-Escribano, J.M., Benito, B., Antón, R. \& Ruiz-Barajas, S., 2015. Relationships between $\mathrm{Mw}$ and other earthquake size parameters in the Spanish IGN Seismic Catalog, Pure appl. Geophys., 172, 2397-2410.

Crespo-Martín, C. \& Martín-González, F., 2019. Intraplate sequences and swarms: statistical analysis of intraplate region (Galician, NW Iberian Peninsula), in Int. Conf. Commemoration of 20th Anniversary of the 1999 Chi-Chi Earthquake, NCREE-Narlabs-TEC, Taiwan.

De Vicente, G., Cloetingh, S., Muñoz-Martín, A., Olaiz, A., Stich, D., Vegas, R., Galindo-Zaldivar, J. \& Fernandez-Lozano, J., 2008. Inversion of moment tensor focal mechanisms for active stresses around the microcontinent Iberia: Tectonic implications, Tectonics, 27, TC1009, doi:10.1029/2006TC002093.

Galindo-Zaldivar, J., González-Lodeiro, F. \& Jabaloy, A., 1993. Stress and palaeostress in the Betic-Rif cordilleras (Miocene to the present), Tectonophysics, 227, 105-126.

González, A., 2016. The Spanish National Earthquake Catalogue: evolution, precision and completeness, J. Seismol., 21, 435-471.

Gulia, L., Wiemer, S. \& Wyss, M., 2012. Catalog Artifacts and Quality Controls, Community Online Resource for Statistical Seismicity Analysis, doi:10.5078/corssa-93722864, Available at http://www.corsa.org.

Hainzl, S. \& Fischer, T., 2002. Indications for a successively triggered rupture growth underlying the 2000 earthquake swarm in Vogland/NW Bohemia, J. geophys. Res., 107, 1-9, doi:10.1029/2002JB001865.

Hainzl, S., 2004. Seismicity patterns of earthquake swarms due to fluid intrusion and stress triggering, Geophys. J. Int., 159, 1090-1096.

Hainzl, S. \& Marsan, D., 2008. Dependence of the Omori-Utsu law parameters on main shock magnitude: observations and modeling, J. geophys. Res., 113, B10309, doi:10.1029/2007JB005492.

Hainzl, S. \& Ogata, Y., 2005. Detecting fluid signals in seismicity data through statistical earthquake modelling, J. geophys. Res., 110, B05S07, doi:10.1029/2004JB003247.

Hainzl, S., Zakharova, O. \& Marsan, D., 2013. Impact of aseismic transients on the estimation of aftershock productivity parameters, Bull. seism. Soc. Am., 103, 1723-1732.

Helmstetter, A. \& Sornette, D., 2003. Importance of direct and indirect triggered seismicity in the ETAS model of seismicity, Geophys. Res. Lett., 30(11), doi:10.1029/2003GL017670.

IGN, 2020. IGN Earthquake Catalogue. Instituto Geográfico Nacional, http: //www.ign.es/web/ign/portal/sis-catalogo-terremotos.

IGN-UPM. 2013. Actualización de Mapas de Peligrosidad Sísmica de España 2012, Centro Nacional de Información Geográfica, Madrid.

Kumazawa, T., Ogata, Y., Kimura, K., Maeda, K. \& Kobayashi, A., 2016. Background rates of swarms earthquakes that are synchronized with volumetric strain changes, Earth planet. Sci. Lett., 442, 51-60.

Lohman, R.B. \& McGuire, J.J., 2007. Earthquake swarms driven by aseismic creep in the Salton Trough, California. J. geophy. Res., 112, B04405, doi:10.1029/2006JB004596.

López-Fernández, C., Pulgar, J.A., Glez-Cortina, J.M., Gallart, J., Díaz, J. \& Ruiz, M., 2004. Actividad sísmica en el noroeste de la Península Ibérica observada por la red sísmica local del Proyecto GASPI (1999-2009), Trab. geol., 24, 91-106.

López-Fernández, C., Pulgar, J.A., Díaz, J., Gallart, J., Glez-Cortina, J.M. \& Ruiz, M., 2012. Seismotectonic characterization of the Becerreá area (NW Spain), Geol. Acta, 10, 71-80.

López, D.L., Araujo, P.A., Delgado, I., Cid, J.A. \& Astray-Dopazo, G., 2015. Geochemistry of hydrothermal systems: thermal springs of Ourense, in Proc. 1st International Congress on Water Healing SPA and Quality of Life, Campus da Auga, Univ. de Vigo, pp. 23-26.
López Fernández, C., Fernández-Viejo, G., Olona, J. \& Llana-Fúnez, S., 2018. Intraplate seismicity in the Northwest Iberia along the trace of the Ventaniella fault: a case for fault intersection at depth, Bull. seism. Soc. Am., 108, 604-618.

Marques, J.M., Espinha Marques, J., Carreira, P.M., Graça, R.C., AiresBarros, L., Carvalho, J.M., Chamine, H.I. \& Borges, F.S., 2003. Geothermal fluids circulation at Caldas do Moledo area, Northern Portugal: geochemical and isotopic signatures. Geofluids, 3, 189-201.

Marsan, D., Prono, E. \& Helmstetter, A., 2013. Monitoring aseismic forcing in fault zones using earthquake times series, Bull. seism. Soc. Am., 103, 169-179.

Marti'n-Gonza'lez, F., 2005. Tecto'nica Alpina, Neotecto'nica y Sismotecto'nica en la Terminacio'n Occidental de los Relieves Canta'bricos (Macizo Ibe'rico). Marco Tecto'nico de las Crisis Si'smicas de Lugo. $\mathrm{PhD}$ thesis, Univ. Complutense, Madrid.

Martín-González, F. \& Heredia, N., 2011. Geometry, structures and evolution of the western termination of the Alpine-Pyrenean Orogen relief (NW Iberian Peninsula). J. Iber. Geol., 37, 102-120.

Martín-González, F., Antón, L., Insua-Arévalo, J.M., De Vicente, G., Martínez-Díaz, J.J., Muñoz-Martín, A., Heredia, N. \& Olaiz, A., 2012. Seismicity and potencially active faults in the Northwest and Central-West Iberian Peninsula, J. Iber. Geol., 38, 31-51.

Martín-González, F., Freudenthal, M., Heredia, N., Martín-Suárez, E. \& Rodríguez-Fernández, L.R., 2014. Paleontological age and correlations of the Tertiary of the NW Iberian Peninsula: the tectonic evolution of a broken foreland basin, Geol. J., 49, 15-27.

Marti'n-Serrano, A., Mediavilla, R. \& Santisteban, J.I., 1996. North-western Cenozoic record: present knowledge and the correlation problem, in Tertiary Basins of Spain: The Stratigraphic Record of Crustal Kinematics, pp. 237-246, Eds. Friend, P.F. \& Dabrio, C.J., Cambridge University Press.

Martínez-Díaz, J.J., Capote, R., Tsige, M., Villamor, P., Martín-González, F. \& Arévalo, J.M., 2006. Seismic triggering in a stable continental area: the Lugo 1995-1997 seismic sequences (NW Spain), J. Geod., 41, 440-449.

Mesimeri, M., Kourouklas, C., Papadimitriou, E., Karakostas, V. \& Kementzetzidou, D., 2018. Analysis of microseismicity associated with the 2017 seismic swarm near the Aegean coast of NW Turkey, Acta Geophys., 66, 479-495.

Mignan, A. \& Woessner, J., 2012. Estimating the Magnitude of Completeness for Earthquake Catalogs, Community Online Resource for Statistical Seismicity Analysis, doi:10.5078/corssa-00180805. Available at http://www.corssa.org.

Mogi, K., 1963. Some discussion on aftershocks, foreshocks and earthquake swarms-the Fracture of a semi-infinite body caused by and inner stress origin and its relation to earthquake phenomena (Third Paper), Bull. Earth. Res. Ins., 41, 615-658.

NCSE, 2002. Normal de Construcción Sismoresistente: parte general y edificación. BOE, 244, 35989-35967

Ogata, Y., 1988. Statistical models for earthquake occurrences and residual analysis for point processes, J. Am. Stat. Assoc., 83, 9-27.

Ogata, Y., 1998. Space-time point process models for earthquake occurrences, Ann. Inst. Stat. Math., 50, 379-402.

Paige, C.C. \& Saunders, M. A., 1982. LSQR: Sparse linear equations and least squares problems, ACM Trans. Math. Softw., 8/2, 195-209.

Passarelli, L. et al., 2016. Erratum: aseismic transient driving the swarm-like seismic sequence in the Pollino range, Southern Italy, Geophys. J. Int., 204, 365-365.

Pe'rez, N.M., Nakai, S., Wakita, H., Albert-Beltra'n, J.F. \& Redondo, R., 1996. Preliminary results on $3 \mathrm{He} / 4 \mathrm{He}$ isotopic ratios in terrestrial fluids from Iberian Peninsula: Seismotectonic and neotectonic implications, Geogaceta, 20, 830-833.

Utsu, T., 1971. Aftershocks and earthquake statistics (II): further investigations of aftershocks and other earthquake sequences based on a new classification of earthquake sequences, J. Fac. Sci., Hokkaido Univ. Ser. 7, Geophys., 3, 197-266.

van Stiphout, T., Zhuang, J. \& Marsan, D., 2012. Seismicity Declustering, Community Online Resource for Statistical Seismicity Analysis, doi:10.5078/corssa-52382934. Available at http://www.corssa.org. 
Vidale, J.E. \& Shearer, P.M., 2006. A survey of 71 earthquake bursts across southern California: exploring the role of pore fluid pressure fluctuations and aseismic slip as drivers, J. geophys. Res., 11, B05312, doi:10.1029/2005JB004034.

Waldhauser, F. \& Ellsworth, W.L., 2000. A double-difference earthquake location algorithm: method and application to the Northern Hayward Fault, California, Bull. seism. Soc. Am., 90, 1353-1368.

Waldhauser, F., 2001. hypoDD - A Program to Compute Double-Difference Hypocenter Locations, U.S. Geological Survey Open-File Report 01-113, 25pp., https://pubs.usgs.gov/of/2001/0113/.

Wiemer, S., 2001. A software package to analyze seismicity: ZMAP. Seismol. Res. Lett., 72, 373-382.

Wolfe, C.J., Brooks, B.A., Foster, J.H. \& Okubo, P.G., 2007. Microearthquake streaks and seismicity triggered by slow earthquakes on the mobile south flank of Kilauea Volcano, Hawai'i, Geophys. Res. Lett., 34, L23306, doi:10.1029/2007GL031625.

Yazdi, P., Hainzl, S. \& Gaspar-Escribano, J.M., 2017. Statistical analysis of the 2012-2013 Torreperogil-Sabiote seismic series, Spain, J. Seismol., 21, 705-717.

Zhuang, J., Ogata, Y. \& Vere-Jones, D., 2002. Stochastic declustering of space-time earthquakes occurrences, J. Am. Stat. Assoc., 97, 369-380.

Zhuang, J., Werner, M.J., Hainzl, S., Harte, D. \& Zhou, S., 2011. Basic Models of Seismicity: spatiotemporal models, Community Online Resource for Statistical Seismicity Analysis, doi:10.5078/corssa-07487583. Available at http://www.corssa.org.

Zhuang, J., Harte, D., Werner, M.J., Hainzl, S. \& Zhou, S., 2012. Basic Models of Seismicity: Temporary models, Community Online Resource for Statistical Seismicity Analysis, doi:10.5078/corssa-79905851. Available at http://www.corssa.org. 